\title{
Melting and Crystallization Behaviors of Poly(lactic acid)/Polypropylene Blends
}

\author{
Zhi-Fei BAI ${ }^{\mathrm{a}}$, Qiang DOU ${ }^{\mathrm{b}}$
}

College of Materials Science and Engineering, Nanjing Tech University, Nanjing 210009, China

azhifeibai@126.com, 'bouqiang.njut@163.com

${ }^{*}$ Corresponding author

Keywords: Crystallization, Poly(lactic acid), Polypropylene, Blend.

\begin{abstract}
The melting and crystallization behaviors of poly(lactic acid) (PLA)/polypropylene (PP) and PLA/PP/PP-graft-maleic anhydride (PP-g-MAH) blends were investigated by means of differential scanning calorimetry (DSC) and polarized light microscopy (PLM). The results showed that the pure PLA and the PLA in the blends were very difficult to crystallize during the cooling process. PP-g-MAH had a weak restraint on the non-isothermal crystallization of the blends but it promoted the growth of the spherulites during isothermal crystallization process. It was also found that blending PLA with PP decreased the size of spherulites.
\end{abstract}

\section{Introduction}

Due to the diminishing resources and the increasing environmental problems, much attention has been focused on biodegradable polymers that can be produced from renewable resources. Poly(lactic acid) (PLA), one of the biodegradable linear aliphatic thermoplastic polyester, has been studied extensively due to its biodegradability, biocompatibility and processability [1-3]. Moreover its mechanical properties are comparable to those of petroleum-based polymers, making it suitable for commodity products such as clothing, textiles, packaging materials, agriculture, forestry, civil engineering and so on [4-6]. However, PLA has some shortcomings such as brittleness and low heat deflection temperature, which restricts its applications in niche markets [2,7-8]. Polypropylene (PP) is a petroleum-based polymer with a combination of outstanding physical, chemical, mechanical, thermal and electrical properties. Blending PLA with PP is the most practical and economical way to modify the physical properties of PLA and improve the biodegradability of PP [9]. Hamad et al. [9] prepared PLA/PP blends and studied their rheological and mechanical characterization. Choudhary et al. [8] found that PLA/PP blend is immiscible because of the high polarity difference between the components. In general, blending with a compatibilizer such as polypropylene-grafted maleic anhydride (PP-g-MAH) is the most effective method to increase the miscibility of the polymer blends $[8,10]$.

In this study, PLA/PP and PLA/PP/PP-g-MAH blends were prepared via melt blending. The melting and crystallization behaviors of the blends were investigated.

\section{Experimental}

\section{Materials}

PLA (4032D, density: $1.25 \mathrm{~g} \cdot \mathrm{cm}^{-3}, \mathrm{MFR}=7.5 \mathrm{~g} / 10 \mathrm{~min}$ at $230^{\circ} \mathrm{C}$ and $2.16 \mathrm{Kg}$, Nature Works, USA), PP (T30S, MFR $=3.0 \mathrm{~g} / 10 \mathrm{~min}$ at $230^{\circ} \mathrm{C}$ and $2.16 \mathrm{Kg}$, PetroChina Jingmen Petrochemical Co., Ltd., Jingmen, China), PP-g-MAH (MAH grafting ratio $=0.3 \mathrm{wt} \%$, MFR $=50 \mathrm{~g} / 10 \mathrm{~min}$ at $230^{\circ} \mathrm{C}$ and 2.16 Kg, Nanjing Qiangren Plastics Co., Ltd., Nanjing, China), and industrial antioxidant (B215, Nanjing Hua Lim Chemical Co., Ltd., Nanjing, China) were commercially available.

\section{Preparation of Samples}

PLA, PP and PP-g-MAH were dried under vacuum at $80^{\circ} \mathrm{C}$ for $8 \mathrm{~h}$ before compounding. PLA/PP and PLA/PP/PP-g-MAH blends were prepared in an internal mixer (HL200, Jilin University 
Science \& Technology Equipment Factory, Changchun, China) at $200^{\circ} \mathrm{C}$ and a rotation speed of 40 rpm for 5 minutes. 0.2 mass\% B215 (based on the blend) was added during the melt blending. The melt was cooled and cut into small pieces.

A small piece was placed between two glass slides on a hot stage kept at $210^{\circ} \mathrm{C}$ for 5 min to make the sample to melt completely and remove thermal history. It was squeezed on the top slide to form a film and was quickly transferred onto a hot stage kept at $120^{\circ} \mathrm{C}$ for $30 \mathrm{~min}$. Finally, the film was quenched to room temperature. The thickness of the samples after isothermal crystallization was about $0.5 \mathrm{~mm}$ for differential scanning calorimetry (DSC) measurement and 10-20 $\mu \mathrm{m}$ for polarized light microscopy (PLM) observation, respectively.

\section{DSC Measurements}

The melting and crystallization behaviors of the isothermally crystallized samples were measured using a DSC apparatus (ZF-DSC-D2, Shanghai Zufa Industry Co., Ltd., Shanghai, China) under a dry nitrogen atmosphere. The instrument was calibrated with pure indium, tin and zinc for temperature and heat flow, respectively. For each measurement, $\sim 4 \mathrm{mg}$ of the sample was sealed in an aluminum pan. The sample was heated from room temperature to $210^{\circ} \mathrm{C}$ at $10^{\circ} \mathrm{C} / \mathrm{min}$, and held at $210^{\circ} \mathrm{C}$ for $5 \mathrm{~min}$ to remove the thermal history. Then, the melted sample was cooled to $50^{\circ} \mathrm{C}$ at $10^{\circ} \mathrm{C} / \mathrm{min}$, and held at $50^{\circ} \mathrm{C}$ for $5 \mathrm{~min}$. At last, the sample was reheated to $210^{\circ} \mathrm{C}$ at $10^{\circ} \mathrm{C} / \mathrm{min}$. The melting and cooling curves were recorded. The melting temperature $\left(T_{\mathrm{m}}\right)$, cold crystallization temperatures $\left(T_{\mathrm{cc}}\right)$, and the enthalpies of melting $\left(\Delta H_{\mathrm{m}}\right)$ and cold crystallization $\left(\Delta H_{\mathrm{cc}}\right)$ were determined from the melting curves. The crystallization temperatures $\left(T_{\mathrm{cp}}\right)$ and the enthalpies of crystallization $\left(\Delta H_{\mathrm{c}}\right)$ were determined from the cooling curves.

\section{PLM Observations}

Spherulitic morphologies of the isothermally crystallized samples were observed using a PLM (LW-200-4JS, Shanghai LW Scientific Co. Ltd, Shanghai, China) equipped with crossed polars and a CCD camera. Pictures were captured and stored in a computer.

\section{Results and discussion}

\section{DSC Measurements}

The melting curves of the isothermally crystallized samples are shown in Fig. 1. The relevant parameters are presented in Table 1 . There were double melting peaks in the first melting curve for PLA/PP (80/20), PLA/PP/PP-g-MAH (40/48/12), PLA/PP/PP-g-MAH (60/32/8) and PLA/PP/PP-gMAH (80/16/4) blends and the pure PLA. The imperfect crystals of PLA in the samples recrystallized during the first heating process, thus double melting peaks appeared. The peak at lower temperature resulted from the original crystals, while the peak at higher temperature was attributed to the recrystallized ones of the original crystals [11].

In the second melting curves (Fig. 1(b)), the cold crystallization peaks appeared in the pure PLA and PLA/PP/PP-g-MAH blends, indicating that the PLA chains did not crystallize during the cooling process. Compared with PLA/PP blends, PLA/PP/PP-g-MAH blends showed the cold crystallization peaks because chain mobility of PLA decreased after the addition of PP-g-MAH into the blends. Moreover, $T_{\mathrm{cc}}$ shifted to higher temperatures with the PLA content in PLA/PP/PP-gMAH blends. The first and second heating curves were different because of the different thermal history that the samples suffered.

In the cooling curves (Fig. 2), the pure PP showed a very sharp crystallization peak at $109.6^{\circ} \mathrm{C}$. The crystallization areas of the blends decreased with the PLA content due to the low crystallization rate of PLA in blends. Meanwhile, $\triangle \mathrm{Hc}$ values of PLA/PP/PP-g-MAH blends were lower than those of PLA/PP blends, indicating that PP-g-MAH restricted the crystallization of PP in blends. Moreover, the cooling curve for PLA was very smooth and no crystallization peak can be observed because the crystallization rate of the pure PLA was very slow at this cooling rate. 


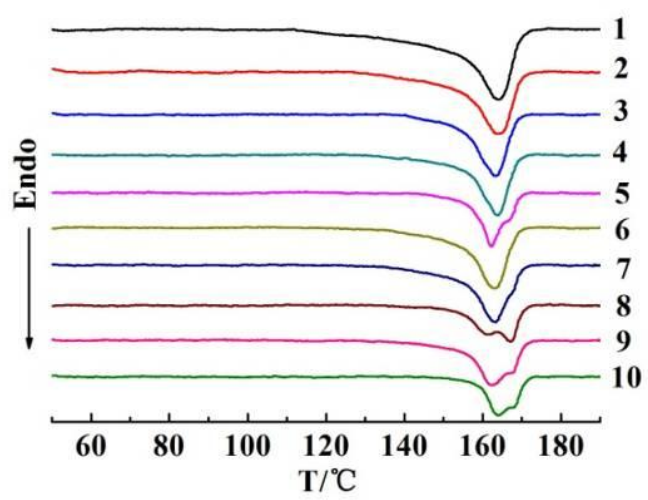

(a) the first melting curves



(b) the second melting curves

PLA/PP/PP-g-MAH: 1-0/100/0; 2-20/80/0; 3-40/60/0; 4-60/40/0; 5-80/20/0; 6-20/64/16; $7-40 / 48 / 12 ; 8-60 / 32 / 8 ; 9-80 / 16 / 4 ; 10-100 / 0 / 0$

Fig. 1 DSC melting curves of the isothermally crystallized samples

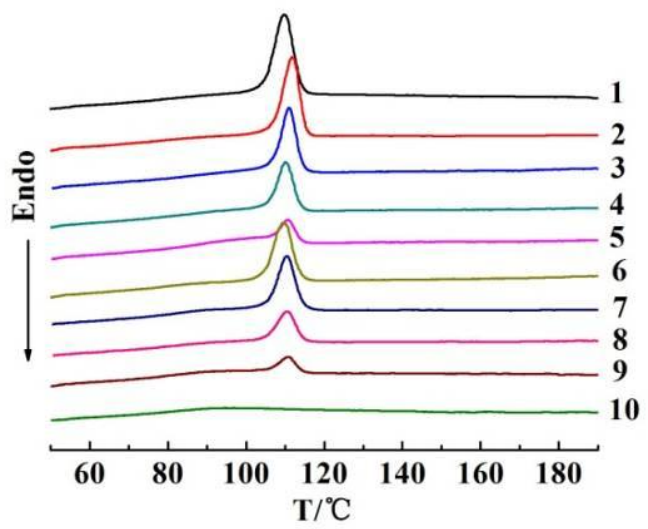

PLA/PP/PP-g-MAH: 1-0/100/0; 2-20/80/0; 3-40/60/0; 4-60/40/0; 5-80/20/0; 6-20/64/16; $7-40 / 48 / 12 ; 8-60 / 32 / 8 ; 9-80 / 16 / 4 ; 10-100 / 0 / 0$

Fig. 2 DSC cooling curves of the isothermally crystallized samples

Tab. 1 Thermal parameters of the isothermal crystallization samples

\begin{tabular}{ccccccccc}
\hline $\begin{array}{c}\text { PLA/PP/ } \\
\text { PP-g- } \\
\text { MAH }\end{array}$ & \multicolumn{2}{c}{ first melting } & \multicolumn{3}{c}{ second melting } & \multicolumn{2}{c}{ cooling } \\
\cline { 2 - 9 }$\left[{ }^{\circ} \mathrm{C}\right]$ & $\Delta H m[\mathrm{~J} / \mathrm{g}]$ & $T_{\mathrm{cc}}\left[{ }^{\circ} \mathrm{C}\right]$ & $\begin{array}{c}\Delta H c c \\
{[\mathrm{~J} / g]}\end{array}$ & $T_{\mathrm{m}}\left[{ }^{\circ} \mathrm{C}\right]$ & $\Delta H m$ & $T_{\mathrm{cp}}$ & $\Delta H c$ \\
\hline $0 / 100 / 0$ & 163.9 & 89.38 & - & - & 162.7 & 79.06 & 109.6 & 95.01 \\
\hline $20 / 80 / 0$ & 164.2 & 60.38 & - & - & 162.7 & 66.40 & 111.9 & 90.13 \\
\hline $40 / 60 / 0$ & 163.5 & 53.37 & - & - & 161.9 & 49.51 & 110.7 & 66.76 \\
\hline $60 / 40 / 0$ & 163.7 & 45.91 & - & - & 163.1 & 46.72 & 110.0 & 51.72 \\
\hline $80 / 20 / 0$ & $162.4,166.9$ & 37.48 & - & - & $162.3,166.5$ & 35.93 & 110.3 & 36.97 \\
\hline $20 / 64 / 16$ & 162.7 & 57.68 & - & - & 162.7 & 56.43 & 109.6 & 78.34 \\
\hline $40 / 48 / 12$ & $163.1,168$ & 55.74 & 96.5 & 15.19 & $163.1,166.9$ & 54.39 & 110.4 & 52.45 \\
\hline $60 / 32 / 8$ & $161.1,166.9$ & 51.17 & 98.9 & 18.08 & $160.8,166.5$ & 45.91 & 110.3 & 41.83 \\
\hline $80 / 16 / 4$ & $162.3,167.7$ & 49.18 & 106.6 & 20.14 & $161.6,166.5$ & 43.29 & 110.7 & 30.91 \\
\hline $100 / 0 / 0$ & $163.9,168.4$ & 31.02 & 110.7 & 27.35 & $162.7,167.7$ & 33.04 & - & - \\
\hline
\end{tabular}

\section{PLM Observations}

Fig. 3 shows PLM micrographs of the isothermally crystallized samples. As can be seen, the pure PP showed common spherulitic structure with a diameter of about 50-70 $\mu \mathrm{m}$ and the pure PLA exhibited perfect Maltase extinction crosses and the spherulitic size was about $100 \mu \mathrm{m}$. 
Compared with the pure PLA or PP, the spherulitics size of PLA/PP blends was smaller. Meanwhile, the spherulitics size decreased with the PLA content. For PLA/PP (60/40) blend, the spherulitic size was so fine that it was hard to be figured out. The results indicated that the spherulitics of PLA and/or PP impinged into each other which led to the denser spherulitic population. The similar results were reported by H.W. Xiao et al. and M.T. Run et al. [12-13]. However, the spherulitic size of PLA/PP/PP-g-MAH blends were larger than that of PLA/PP blends, which implied that PP-g-MAH promoted the growth of the spherulites during the isothermal crystallization process.



(a) pure PP



(c) PLA/PP (40/60)

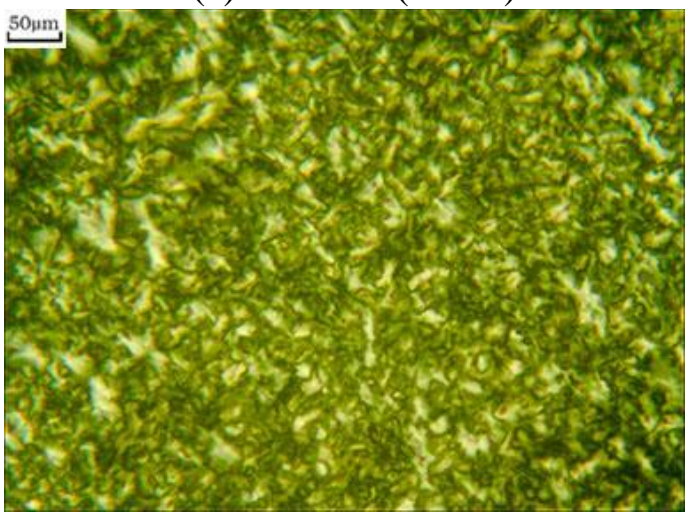

(e) PLA/PP/PP-g-MAH (40/48/12)

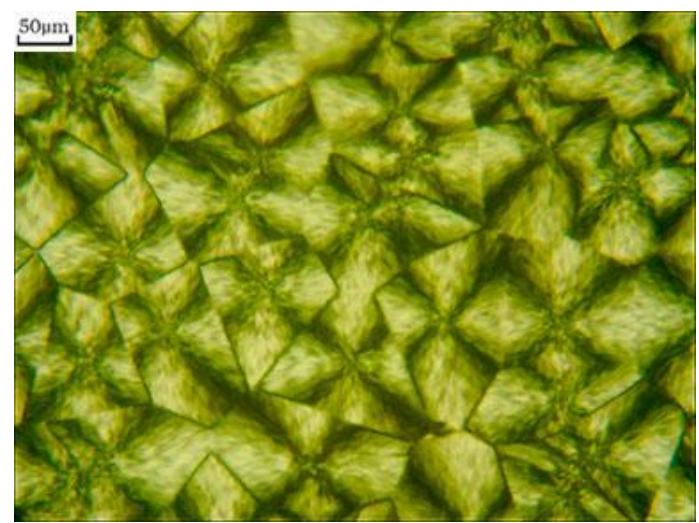

(b)pure PLA



(d) PLA/PP (60/40)

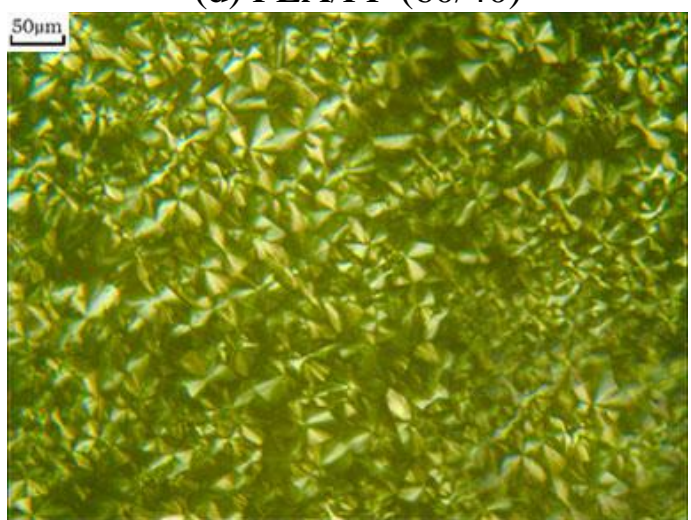

(f) PLA/PP/PP-g-MAH (60/32/8)

Fig. 3 PLM micrographs of the isothermally crystallized samples

\section{Conclusions}

In this paper, melting and crystallization behaviors of PLA/PP and PLA/PP/PP-g-MAH blends were investigated. DSC results indicated that the pure PLA and the PLA in the blends were very difficult to crystallize during the cooling process. Meanwhile, the presence of PP-g-MAH decreased the chain mobility of PLA and restricted the crystallization of PP. PLM observations showed that 
blending PLA with PP decreased the size of spherulites and PP-g-MAH had a promotion on growth of spherulites during the isothermal crystallization process.

\section{References}

[1]C. Li and Q. Dou: Thermochim. Acta Vol. 594 (2014), p. 31.

[2]N. Shi and Q. Dou: J. Therm. Anal. Calorim Vol. 119 (2015), p. 635.

[3]P.M. Chou, M. Mariatti, A. Zulkifli and M. Todo: Polym. Bull Vol. 69 (2012), p. 455.

[4]T. Gerard and T. Budtova: Eur. Polym. J Vol. 48 (1992), p. 1110.

[5]R. Auras, B. Harte and S. Selke: Macromol. Biosci Vol. 4 (2004), p. 835.

[6]P. Pan, J Yang, G. Shan, Y. Bao, Z. Weng, A. Cao, K. Yazawa and Y. Inoue: Macromolecules Vol. 45 (2012), p. 189.

[7]R. Jaratrotkamjorn, C. Khaokong and V. Tanrattanakul: J. Appl. Polym. Sci Vol. 124 (2012), p. 5027.

[8]P. Choudhary, S. Mohanty, S.K. Nayak and L. Unnikrishnan: J. Appl. Polym. Sci Vol. 121 (2011), p. 3223.

[9]K. Hamad, M. Kaseem and F. Deri: J. Polym. Res Vol. 18 (2011), p. 1799.

[10]D. Shi, J. Yang, Z. Yao, Y. Wang, H. Huang, W. Jing, J. Yin and G. Costa: Polymer Vol. 42 (2011), p. 5549.

[11]T. Shieh and G.L. Liu: J. Polym. Sci. Part B: Polym. Phys Vol. 45 (2007), p. 466.

[12]H. Xiao, W. Lu and J.T. Yeh: J. Appl. Polym. Sci Vol. 112 (2009), p. 3754.

[13]M. Run, X. Hu and J. Gao: Acta. Polymerica. Sinica Vol. 12 (2007), p. 1121. 